\title{
Electricity Production using Smart Piezoelectric Crystals
}

\section{Suriya $\mathrm{VN}^{*}$ and Sivakumar S}

Department of Mechanical Engineering, Dhanalakshmi Srinivasan Engineering College, Perambalur, Tamilnadu, India

\begin{abstract}
With the increase in energy consumption due to ever grown number of electrical devices, Harvesting for reusable clean, non-polluting energy source lot of mechanical motion and energy available at every second of human life in the work of converting mechanical energy into electrical energy, piezoelectric crystals are Most Advantage in this type of energy conversion its complete green energy process. In this context, we are proposing the prototype of a piezoelectric generator that harvests mechanical vibrations energy available on a Staircase. Embarked piezoelectric transducer, which is an electromechanical converter, undergoes mechanical vibrations therefore produce electricity .
\end{abstract}

Keywords: Piezoelectric; Electricity; Footstep; Current; Quartz

\section{Introduction}

Due to soaring energy prices and an increased environmental awareness there is a growing need for sustainable designs. The world around us has embraced this concept by incorporating solar panels, wind turbines and promoting shared transportation via zip cars. Instead of looking for new ways to generate energy, we will be focusing on harvesting energy from everyday activities that would otherwise be lost. A person exerts lots of force when they walk down the stairs. The staircase power harvesting system intends to turn this energy into electrical power using a piezo-electric generator. There are lots of machines available to convert mechanical energy into electrical energy. The dynamo is best available converter but it's used for limited applications but the smart materials available that is known as piezo electric crystals. The crystals produce piezo electric effect and converse piezo electric effect [1]

\section{Smart Materials}

Smart Materials means which adjust to the requirements. It responds to environmental requirement with particular changes in some variables. If a materials can experience a heat, light, pressure, electricity, magnetic field and respond and respect to the vary environments. There are lot of type of Smart materials are Available. Some of listed here;

1.Piezo Electric Materials

2.Thermo electrical Materials

3.Electro strictive Materials

4.Shape Memory Alloy Materials

5.Magneto Strictive Materials

6.Photo Voltaic Materials

Then use the Material to compose artificial muscle, Airbag Sensor, Aircraft Blades. It is the modern Material can sense the environment and produce the response.

\section{Piezoelectric Effect}

PiezoElectric crystals are quartz and tourmaline and rochells salt. The Crystal has a hexagonal shape with at both ends. It has three axis, there are Optical Axis and Electrical Axis and Mechanical Axis.

When a pressure or mechanical force is applied along the piezo electric crystals, then it Produce the electricity. Its known as piezo electric effect.
When E.m.f is applied on piezo electric crystals, then the crystals start vibrating or show a mechanical expansion and contraction. It is known as inverse piezo electric effect.

\section{Production of Electricity}

By using the piezo electric crystals, we can generate the electricity. The electricity we suggest to use piezo electric crystals to produce electricity [2]. Our idea is there is lot of mechanical movement available on Our Road Transportation. Human and Vehicle Transportation are along the road. By installing the piezo electric crystal in Roads can Generate Constant Electricity. In this type of Road, We should Divide Road to Four Layers [3]. Very lower Layer is Vibrating Plates and middle of Layer is deploying Piezo Electric Crystals. Upper layer is Vibrating Plates and Very Upper Layer is Road. This is Construction of Electricity Producing Road. If the Human or Vehicles are Travelling along the road. They produce the Pressure on vibrating Plates [4]. Vibrating plates can deliver the pressure to Crystals. The crystal produces the electricity by the piezo electric crystals.

\section{What is our Thought}

In our India, We have lot of transportation Available in the Holy places and Railway Junction and Children Parks and Important People Junction Points. The Transportation Produce Electricity by the Transportation along the road.

\section{Disadvantages}

The vibrating plates can't deliver constant pressure over crystals. Crystals can be improved for withstand the high pressure or Mechanical Stress.

\section{Conclusion}

In India our border roads are so long. We need constant protection on borders. So we can use the piezo electric crystallized

*Corresponding author: Suriya VN, Department of Mechanical Engineering, Dhanalakshmi Srinivasan Engineering College, Perambalur, Tamilnadu, India, Tel: 04328220554; E-mail: suryavn91@yahoo.com

Received March 30, 2015; Accepted September 19, 2015; Published September 29, 2015

Citation: Suriya VN, Sivakumar S (2015) Electricity Production using Smart Piezoelectric Crystals. J Appl Mech Eng 4: 177. doi:10.4172/2168-9873.1000177

Copyright: $\odot 2015$ Suriya VN, et al. This is an open-access article distributed under the terms of the Creative Commons Attribution License, which permits unrestricted use, distribution, and reproduction in any medium, provided the original author and source are credited. 
Citation: Suriya VN, Sivakumar S (2015) Electricity Production using Smart Piezoelectric Crystals. J Appl Mech Eng 4: 177. doi:10.4172/21689873.1000177

Page 2 of 2

road technology because its act as best sensor. So we easily found the enemies infiltrations. If the technology come to existence there is every man have a chance to be an electricity generation factory. That is not a dream but it's possible by smart piezo electric crystals. It can be viewed as next promising source of electricity.

\section{References}

1. Mimazara E, Vasic D, Costa F (2008) Conference Proceedings, Piezoelectric
Generator harvesting bike vibration energy to supply portable devices, ICREPQ.

2. Singh UK, Middleton RH (2007) Piezoelectric power scavenging of mechanical vibration energy, Australian Mining Technology Conference 111-118.

3. Roundy S, Wright PK, Rabaye J (2003) A study of lowlevel vibrations as a power source for wireless sensor nodes Computer Communications 26: 11311144.

4. Anton SR, Sodano HA (2007) A review of power harvesting using piezoelectric materials (2003-2006) Smart Materials and Structures 16: R1-R21. 